\title{
La vivienda estatal y su contribución al fomento de la familia nuclear. El caso de Mendoza durante la primera mitad del siglo $X X$
}

\author{
[State-Funded Housing and its Contribution to the Promotion of the \\ Nuclear Family: Mendoza's Case in the First Half of the 20th Century] \\ Verónica Cremaschi \\ (Instituto de Ciencias Humanas, Sociales y Ambientales, CONICET) \\ vcremaschi@mendoza-conicet.gob.ar
}

\begin{abstract}
Resumen
El presente trabajo propone explorar la vivienda en Mendoza durante la primera mitad del siglo XX y su consolidación como una herramienta del Estado para impulsar un modelo familiar deseado. Para evidenciar este proceso retomamos el problema en clave histórica analizando tanto la materialidad de las viviendas estatales como los discursos en torno a ella encontrados en distintas fuentes. Al respecto, es posible afirmar que a partir de la década de 1930 existieron distintos esfuerzos oficiales tendientes a regular la convivencia familiar por medio de la implementación de tipologías habitacionales unifamiliares. Consideramos que este proceso encontró su punto más álgido con el primer peronismo (1946-55) y la concreción masiva de la vivienda mínima promovida por el Estado. Este impulso fue respaldado por distintas opiniones vertidas en la prensa y por propagandas que circularon en medios masivos en general.
\end{abstract}

Palabras clave: Familia Nuclear - Tipología de Vivienda - Estado

\begin{abstract}
This paper discusses state-funded housing as a tool used by the state to promote a specific nuclear family model in Mendoza during the first half of the 20th century. We focus on the evolution of this effort through time, analyzing the physical housing projects carried out by the state, and the discourses created around them, as they can be found in different sources. Findings suggest that, starting in the 1930s, the state used state-funded single-family housing as a tool to encourage the strengthening of the nuclear family. This process reached its highest point during first Perón's administration (194655), when a massive number of basic singlefamily houses were built. This state effort was supported both by the independent press, and by mass media state propaganda.
\end{abstract}

Keywords: Nuclear Family - Housing Typology - State

Recibido: 23/02/2018

Evaluación: 26/06/2018

Aceptado: 03/09/2018

Anuario de la Escuela de Historia Virtual - Año 9 - No 14 - 2018: pp. 53-80.

ISSN: 1853-7049

http://revistas.unc.edu.ar/index.php/anuariohistoria 


\section{La vivienda estatal y su contribución al fomento de la familia nuclear. El caso de Mendoza durante la primera mitad del siglo $X X$}

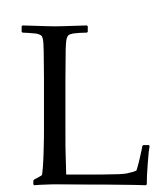

as viviendas son bienes materiales en los que confluyen distintas problemáticas de la esfera privada y pública y de los que pueden inferirse aspectos de la vida cotidiana y simbólica de las sociedades que las producen. En el ámbito de lo privado, la casa identifica la capacidad de ahorro y consumo de una familia ${ }^{1} \mathrm{y}$, por lo tanto, es un símbolo de status y de distinción social (Ballent, 2001, p. 319). Es un bien material que se expone a la percepción de todos (como la vestimenta) de manera duradera y que expresa el ser social de su propietario, sus "medios" y sus gustos (Bourdieu, 2001, p. 34). Además, en las viviendas se plasman las expectativas que se tienen respecto a la familia (Ballent y Liernur, 2014, p. 20). Sin embargo, es importante tener en cuenta que este proceso de identificación de la familia con la unidad doméstica no es universal, sino que es una característica típica de las sociedades capitalistas, que promueven que los miembros de la familia nuclear ${ }^{2}$ vivan juntos (Gil Montero, 2007, p. 90). En lo que hace a la esfera de lo público, más que otros temas disciplinares, la vivienda está imbricada con problemas sociales, urbanísticos y simbólicos de las ciudades de inicios del siglo XX (Cirvini, 2004, p. 194). En consecuencia, constituye un objeto material y simbólico importante en la construcción de los imaginarios sociales.

A partir de estas nociones, en este trabajo nos interesa indagar en el escenario doméstico, entendiéndolo como ámbito en el que se produce el cruce entre la historia de la vivienda y la historia de la familia (Aboy, 2008, p. 356). Más precisamente, debido a la idea de que las condiciones materiales del hogar han sido la influencia más visible y homogeneizadora de la vida familiar, nos interesamos en el papel del Estado en su intento por regular las prácticas de convivencia no deseables a partir del impulso dado a ciertas tipologías de vivienda que fomentaban el modelo unifamiliar (Pérez, 2012, pp. $23,41)$.

Así, desde inicios del siglo $\mathrm{XX}$, de todos los modelos de viviendas existentes, el de planta compacta, considerado "moderno", fue el que intentó imponerse por medio de

\footnotetext{
${ }^{1}$ Si bien el concepto de familia debe entenderse en su contexto histórico y situación socio cultural, cuando empleemos este término nos referiremos de forma amplia a un grupo de personas que interactúan en forma cotidiana y permanente con la finalidad de asegurar su reproducción biológica, la preservación de su vida y las prácticas que aseguren la optimización de su condición social (Torrado, 2003, p. 37).

2 Según la clasificación de Torrado, familia nuclear o neolocal es aquella constituida por el núcleo conyugal, que al momento de formarse fija un lugar de residencia independiente de otros parientes (Torrado, 2003, p. 406).
} 
55 | La vivienda estatal y su contribución al fomento...

los planes habitacionales estatales. Si bien algunas opiniones afirman que su adopción fue parcial, ya que observan continuidades con algunas otras formas de habitar de manera contemporánea, se evidencia, sin embargo, una primacía de dicho modelo a nivel de las representaciones y en la consiguiente difusión de ciertos modos de habitar y domesticidad ideales (Pérez, 2012, p. 50).

En lo que respecta a su aspecto material, Liernur destaca que la configuración de ese dispositivo habitacional "moderno" se constituyó con la especialización de los usos y funciones del habitar doméstico, lo que implicó una separación clara de los espacios de la intimidad y el mundo exterior, proceso que también sucedió en el interior de las casas con la diferenciación de los ambientes. Según este autor, la mencionada distinción comenzó a fines del siglo XIX y se caracterizó por el empleo de formas, dimensiones, texturas, colores y equipamientos particulares para cada habitación (Liernur, 1999, pp. 101, 105). Ballent resalta que las superficies y aberturas se ampliaron en tamaño y cantidad con el fin de asegurar la entrada de la luz solar y la renovación del aire, se produjo la reducción de las alturas de locales, el mayor empleo de superficies y paramentos lisos, la preferencia por colores claros y por los materiales impermeables y lavables en locales sanitarios. La provisión de servicios como el agua y la luz permitió que la cocina y el baño se instalaran en el interior de la vivienda, posibilitando el desarrollo de todas las funciones domésticas dentro de la unidad (Ballent, 2001, p. 321). Esto contribuyó a la compactación de la planta, proceso que también fue impulsado por el incremento del valor de la tierra, lo que condicionó el tamaño de las superficies cubiertas y de los lotes.

En Mendoza los estudios sobre problemas habitacionales han sido poco explorados (Cerdá, 2011, p. 180), pero, sin embargo, se destacan las investigaciones de Raffa (2004), Cerdá (2011, 2007/8, s/f), Schmulevich et al. (2014), Richard-Jorba (2011), Manzini (2011a, 2011b, 2012), Raffa y Manzini (2014) y Cirvini y Manzini (2010 y en prensa). Estos trabajos han ahondado mayormente en los aspectos materiales de las viviendas y no los han analizado en profundidad en relación a los procesos del habitar. Por ello, resulta importante indagar en los discursos que se constituyeron en torno a ellas y que complementan las indagaciones sobre la materialidad arquitectónica, explicando las tipologías y el empleo de ciertos materiales. Al respecto, no hemos detectado en otras provincias cuyanas trabajos producidos desde este enfoque $y$, por ello, consideramos que este artículo permite completar el mapa de investigaciones realizadas desde esta perspectiva que se han centrado mayormente en el área pampeana.

Dentro de las particularidades de Mendoza, cabe destacar la pervivencia de los conventillos hasta bien entrado el siglo XX, su combate por parte de la opinión pública y la inacción estatal al respecto. Sin embargo, durante la década de 1930 se concretó un proyecto experimental de Casas Colectivas, que, para la época, fue expuesto como un ejemplo a nivel nacional en el I Congreso Argentino de Urbanismo (1935) (Raffa, 2010, p. 21). Asimismo, durante el peronismo, observamos la creación pionera (ya que ninguna otra provincia había instaurado un sistema descentralizado) del Instituto Provincial de 
la Vivienda (IPV) 3 en 1947, que poseía presupuesto propio y autonomía. Esta creación generó un importante marco legal en torno a la vivienda estatal, además de permitir concretar un gran número de unidades nuevas y de colocar el tema en una posición central dentro de las propuestas de los gobernadores de esos años. Asimismo, es posible afirmar que, en la primera mitad del siglo XX, la atención dada a la problemática habitacional fue acompañada por disquisiciones en el ámbito teórico y opiniones vertidas en medios de prensa y discursos gubernamentales.

Dado el estado de las investigaciones sobre el tema, en este trabajo intentamos poner en tensión la visión que presenta el acceso a la vivienda como un indicador de la inclusión social por parte de los gobiernos de la primera mitad del siglo XX, para presentarla, en cambio, como una herramienta tendiente a orientar ciertas conductas sociales consideradas indeseadas y afianzar un modelo familiar determinado. Para ello, consideramos interesante analizar cómo fue consolidándose este modelo de habitar moderno en la provincia de Mendoza y cómo el mismo constituyó un prototipo que le permitió al Estado impulsar la familia nuclear. En este sentido, este trabajo se inserta en lo que Susana Torrado (2003, p. 17) define como la línea centrada en las relaciones entre la familia y el Estado, al interesarse en evidenciar uno de los mecanismos que ha empleado este último para influir sobre aquella.

Nuestro corpus de análisis estuvo constituido por artículos de diarios, censos, discursos y labores de gobierno del período tratado. La metodología para acceder a estos textos históricos fue de índole cualitativa y para ello resultaron fundamentales en la interpretación el marco teórico brindado por la hermenéutica y la discursividad social. En este sentido, seguimos a Bajtin (1999, p. 381) al señalar que la comprensión tiene distintos actos, la percepción psicofisiológica del signo físico, su reconocimiento, la comprensión de su significado en un contexto dado, la inclusión en el contexto dialógico y el momento valorativo de comprensión. A su vez, como Verón, consideramos que, mediante el conocimiento de los discursos, es factible interpretar diferentes problemáticas sociales, como las que se relacionan con el habitar, ya que "el análisis de los discursos consiste en la identificación, dentro de la superficie discursiva, de las huellas que remiten a las condiciones de producción de los discursos" (Verón, 2004, p. 201).

Para una mejor comprensión del proceso de consolidación de este modelo impulsado por el Estado, hemos dividido este trabajo en tres partes delimitadas por criterios históricos, cuyo comienzo sucede a inicios del siglo XX, abarca un segundo momento en la década de 1930 y finaliza con el impulso masivo de esta tipología de vivienda durante el primer peronismo (1946-1955).

\footnotetext{
${ }^{3}$ De esta particularidad se desprende que el IPV generara una interesante relación presupuestaria y técnica con el Banco Hipotecario Nacional. Así pues, ambas entidades trabajaron mancomunadamente dentro de las fronteras provinciales.
} 
57 | La vivienda estatal y su contribución al fomento...

\section{La situación habitacional en los primeros años del siglo XX en Mendoza}

Como ha indicado Torrado (2003, p. 25), para comprender los procesos ocurridos en el siglo XX resulta necesario retrotraerse a fines del siglo XIX, momento en que comenzó la organización de la Argentina moderna. Debido a ello es importante destacar que la escasez de viviendas fue un problema crítico desde fines del siglo XIX y principios XX en todo el país, el cual aumentó de forma trascendente en Mendoza con la llegada del ferrocarril en 1885 y con el incremento de la inmigración. Durante los últimos años del siglo XIX y las primeras décadas del XX, la construcción de viviendas y el crecimiento poblacional no tuvieron el mismo dinamismo. El número de casas se incrementó en un $60 \%$ entre los años 1869-1895 y para 1895-1909 solo creció un 12\%; por su parte, el impacto inmigratorio hizo crecer la población en un 77\% entre 1869-95 y en un 139\% entre 1895-1914 (Cerdá, 2011, p. 181). Esto condujo al hacinamiento de la población, sobre todo en los departamentos de producción vitivinícola.

En esta provincia la relación era de 6,53 personas por vivienda en 1869, mientras que en 1909 la cifra ascendió a 13 personas por unidad habitacional (Cerdá, 2011, p. 199). Este número resulta considerable si tenemos en cuenta que, a nivel nacional, el censo de 1895 destacaba que en la Argentina el número de ocupantes por cada edificio era de 7,38 personas, es decir, un guarismo que, si bien era alto, no era tan alarmante como en Mendoza. Esto era percibido como un elemento negativo, dado que no era "favorable a la comodidad y el bienestar de la población, que podría cifrar su anhelo en tener una casa para cada familia." 4 Por otro lado, el Censo de 1909 registró que en Mendoza solo un $50 \%$ de las casas eran ocupadas por sus dueños, un índice que llegó a ser del 32\% en 1947 (Cerdá, 2007/2008, p. 57). Alquilar significaba una dificultad para los trabajadores, puesto que las rentas eran muy costosas e insumían la mitad de un sueldo medio (Cerdá, s/f, p. 21).

Además de la escasez ya planteada, un problema de la época también eran las precarias condiciones de habitabilidad en las que se asilaba la mayoría de la población. Sumadas a la poca cantidad de inmuebles y a los altos alquileres, las viviendas disponibles dejaban mucho que desear en lo que respecta a condiciones constructivas y comodidades. Mendoza se ubicaba por debajo del promedio nacional y detrás de las provincias que componían la región pampeana en lo que se refiere a uso de tecnologías y materiales considerados "modernos" en la construcción (Cerdá, 2011, p. 192). Las viviendas de adobe, que representaban el $75 \%$ en 1869 , se elevaron al $80 \%$ en 1895 , llegando a ser el 90\% en 1909, porcentaje que se mantuvo constante hasta mediados del siglo XX. Esta situación resulta más dramática si se considera la actividad sísmica en la región. En contraste con estas condiciones de habitación, durante las primeras décadas

\footnotetext{
${ }^{4}$ Segundo Censo de la República Argentina.Censos complementarios Tomo III y último. (1895). Buenos Aires: Taller tipográfico de la penitenciaría, p. XXI. Disponible:

http://deie.mendoza.gov.ar/\#!/censos-nacionales-de-poblacion/1895-segundo-censo-nacional-18 (consultado el 9 de agosto de 2018).
}

Anuario de la Escuela de Historia Virtual - Año 9 - N 14 - 2018: pp. 53-80. ISSN 1853-7049 
del siglo $\mathrm{XX}$, comenzaron a realizarse prototipos de construcciones antisísmicas en la provincia, para lo que se propició el uso del hierro y el hormigón armado. Sin embargo, el uso de estas tecnologías constructivas quedó restringido por cuestiones de costos a los estratos sociales altos, mientras que los populares se albergaban en conventillos, ${ }^{5}$ que mayormente eran viviendas de adobe subdivididas, y en las casas de vecindad. Es interesante destacar además que, para entonces, se observaba un creciente interés por temas constructivos y estructurales en los diarios locales (Cremaschi, 2011).

Como se aprecia, en el problema de la habitación popular convergían dos factores: la escasa cantidad y la mala calidad de la misma (Richard-Jorba, 2011, p. 50). Estas condiciones propiciaron la persistencia de pautas de convivencia distintas del modelo nuclear durante la primera mitad del siglo XX, en el cual más de una familia compartía una misma propiedad cuando alquilaban habitaciones en conventillos o rentaban mancomunadamente un inmueble. Esto estaba condicionado no solo por lo económico, sino también por la procedencia rural de los inmigrantes internos que se establecían en las ciudades. Para entonces, era una práctica habitual en muchas de las regiones de origen de los migrantes que toda la familia empleara una sola habitación, costumbre que perduró tanto en el conventillo como en la casa particular (Aboy, 2008, p. 357). En la provincia de Mendoza, la persistencia de la práctica de compartir las unidades habitacionales estaba vinculada con la escasez de vivienda, el encarecimiento de los alquileres, la concentración de la población y otras características propias de la vida urbana de la primera mitad del siglo XX (Cerdá, 2011, p. 200).

Como lo demuestran algunas imágenes de la época y las crónicas de la prensa, en los suburbios de la ciudad, las condiciones de vida resultaban muy adversas (Figura 1), con la existencia de un verdadero cinturón de pobreza urbana.

\footnotetext{
${ }^{5}$ La palabra conventillo aparece, según Mario Sabugo, en España en 1620 y en Buenos Aires en la segunda mitad del siglo XIX. Etimológicamente alude a reunión, ya que "conventum" en latín, se origina en el verbo "convenio", compuesto de "con" y "venire", que significa acudir, reunirse, acordar (Sabugo en Ramos, 1999, p. 23). En Argentina, esta tipología habitacional estaba integrada por habitaciones de alquiler en las que en general proliferaba el hacinamiento y la falta de higiene. Los locatarios compartían baños, cocina y patios.
} 
Figura I. Conventillo mendocino

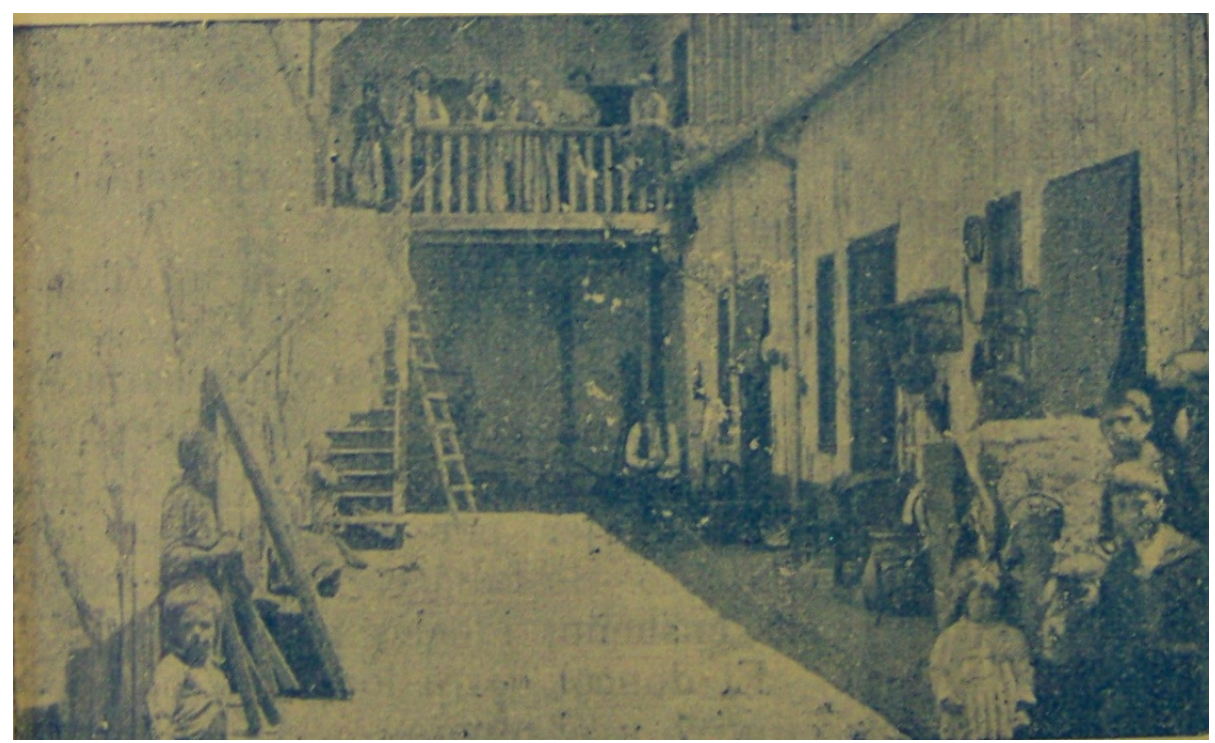

Fuente: Revista La Nueva Era, 1907.

Desde fines del siglo XIX, los higienistas se ocuparon del problema del hacinamiento, estos actores oponían el orden social de las buenas condiciones habitacionales versus la anarquía que reinaba en los conventillos (Cerdá, 2011, p. 184). La condena a la cohabitación, también se percibía en la prensa local que reclamaba por una intervención estatal en la materia: "Existen piezas en las que viven aglomerados hasta siete $\mathrm{u}$ ocho personas. Esto aparte del peligro que encarna para la salud pública, está por completo fuera de nuestras costumbres, y del todo disconforme por el progreso alcanzado". 6

Es interesante detectar cómo también a nivel de los medios, las condiciones de existencia y habitabilidad determinaban y eran las culpables de los problemas sociales, por lo tanto, se resaltaba la relación entre las circunstancias de habitación y las buenas costumbres. De ello dan cuenta distintos artículos en que se hacen afirmaciones como la siguiente: "La promiscuidad corre pareja con la falta de metraje de aire en las habitaciones y todo esto á menudo sin que ni siquiera la inspección municipal lo aperciba". ${ }^{7}$

Como se observa, además de las condiciones de salubridad, estas deficiencias habitacionales traían aparejadas consecuencias en el plano de la moral y las conductas. En este sentido, Liernur considera que "el ideal de aislar a cada familia en su casa propia", que empezó a ser enfatizado y reclamado en esta etapa por distintos sectores sociales, resultó también una alternativa para intentar controlar las formas de

\footnotetext{
${ }^{6}$ Los Andes, 6 de enero de 1910, Las casas de inquilinato, s/p.

${ }^{7}$ Los Andes, 13 de febrero de 1914, Conventillos sin inspección, s/p.
} 
sociabilidad que se sucedían en estos lugares que los convertían en "nidos de rebelión" (Aboy, 2008, p. 357).

Debido a la inquietud despertada a nivel gubernamental por las huelgas y la formación de nuevos movimientos políticos (anarquismo y socialismo), el Estado comenzó a pensar en la vivienda como un dispositivo de integración social para arraigar y homogeneizar a esa masa que constituía la población inmigrante establecida en las ciudades (Ballent, 2001, p. 320). Además de ser centros difusores de ideas consideradas peligrosas, la cohabitación propiciaba la solidaridad, que no se encontraba en la casa individual, en la que la familia construía un lugar que la interiorizaba y, en cierto modo, la aislaba. En el conventillo, el patio obligaba a la interacción entre varios núcleos familiares entre quienes habría cotidianamente conflictos o cooperaciones, pero no indiferencia (Richard-Jorba, 2012, p. 458). El patio era un importante espacio habitacional en el que se desarrollaba gran parte de las actividades y en él los inquilinos compartían la mayor parte del día. Eran espacios de sociabilidad altamente significativos debido a que en ellos convivían personas de distintas nacionalidades o provenientes de distintos lugares del interior, compartiendo comidas, fiestas y luchas reivindicatorias (Ramos, 1999, p. 4). La fotografía número dos (Figura II) nos muestra el patio de un conventillo de los suburbios mendocinos en que existe un grupo de niños en primer plano y una mujer. La edad cercana de los bebés, nos indica la convivencia de más de una familia en la vivienda.

Figura II. Patio de conventillo mendocino

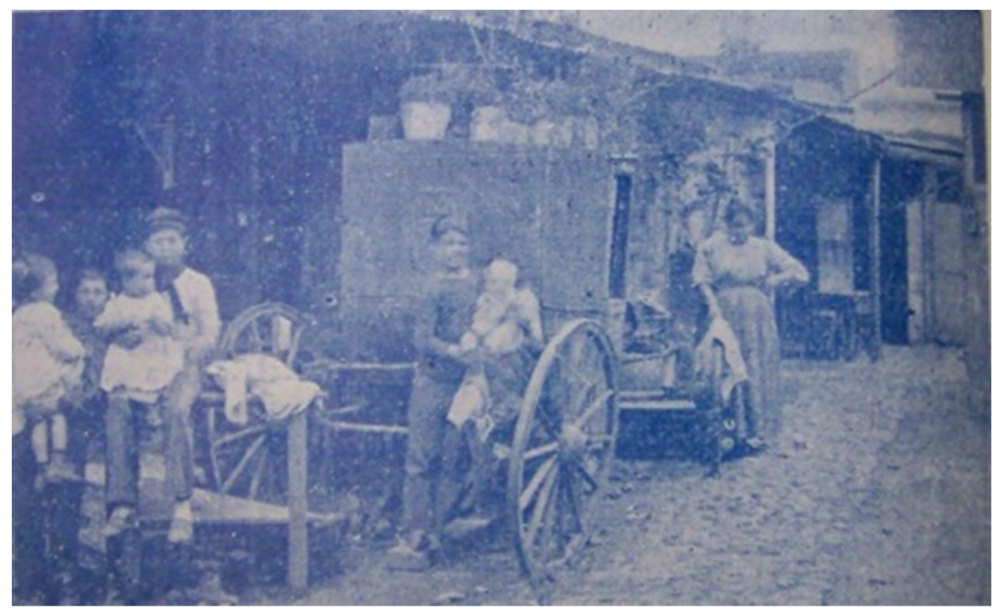

Fuente: Revista La Nueva Era, 1907.

Además de los conventillos, la situación económica adversa y la falta de unidades llevaron a que muchas familias alquilaran dependencias de sus viviendas a amigos, familias extensas o desconocidos para solventar sus gastos, como parte de la supervivencia cotidiana. Esto permitía incrementar ingresos o afrontar alquileres de casas amplias (Cerdá, 2011, pp. 210-212). Es posible apreciar clasificados en diarios de 
61 | La vivienda estatal y su contribución al fomento...

las primeras décadas del siglo $\mathrm{XX}$ que nos proporcionan la pauta de que el ofrecimiento de habitaciones en casas particulares era bastante usual. Algunas de ellas también brindaban un régimen de comidas. Muchas tenían salida a la calle, lo que les otorgaba cierta independencia, aunque se compartían ambientes como los baños y las cocinas. Los avisos frecuentemente delineaban el perfil del inquilino: mujeres, varones, parejas con o sin hijos, nacionalidad, etcétera. ${ }^{8}$

Esto también propició que pervivieran estructuras en las que varias familias o integrantes de distintos grupos familiares habitaban bajo el mismo techo. Eran alternativas a la familia nuclear constituida legalmente, que no era el único modelo, ni el más extendido, como lo demuestra la gran cantidad de hijos ilegítimos y uniones de hecho que predominaban en esos años. En 1869, el censo consignaba que en Argentina había 211 hijos ilegítimos cada mil niños y Mendoza se encontraba entre las provincias con una posición media. ${ }^{9}$ Estos índices ubicaban a la Argentina entre los países con mayor proporción de nacimientos ilegítimos en el mundo. A pesar de los números elevados, este censo contempló los hijos ilegítimos y los amancebamientos como comportamientos marginales a la normatividad instituida desde el punto de vista jurídico y religioso (Cosse, 2004, pp. 20 y 4), lo que nos da la pauta de la visión que sobre esta realidad tenía el Estado. La alta tasa de filiación ilegítima que perduraba a comienzos del siglo XX demuestra la existencia de una diversidad de formas familiares. Estas eran el concubinato, las mujeres mantenidas en la "casa chica" en una relación estable con un hombre que tenía una familia legítima, las uniones libres luego de un fracaso matrimonial y las relaciones inestables instaladas como producto de las dinámicas sociales. Todas realidades que eran bastante distintas a la familia constituida por un matrimonio y los hijos, un ideal homogéneo, que pareció ser favorecido por las élites políticas e intelectuales (Cosse, 2004, pp. 4, 20, 33; 2007, s/p).

Sin embargo, a pesar del diagnóstico de los higienistas y los reclamos en la prensa, recién en la etapa siguiente comenzaron a materializarse en la provincia ejemplos habitacionales que respondían a lo que era todavía una simple solicitud de distintos sectores para solucionar el problema del hacinamiento y la habitación popular. Todavía el problema de la falta de vivienda era justificado por el crecimiento de la población y no se proponían políticas directas de intervención. Se consideraba que se resolvería mediante la activación económica y, por eso, el Estado solo impuso algunas regulaciones que condenaban los modos de habitación que preponderaban, pero no hubo una política social estatal y una de las pocas formas de distribución de la riqueza fue la solidaridad social, influenciada por las ideas asistencialistas decimonónicas (Cerdá, 2011, pp. 60, 213).

\footnotetext{
${ }^{8}$ Los Andes, 25 de septiembre de 1912, Avisos Clasificados, s/p.

9 Primer Censo de la República Argentina. (1869). Buenos Aires. p. XI. Disponible en http://deie.mendoza.gov.ar/\#!/censos-nacionales-de-poblacion/1869-primer-censo-de-la-nacion-argentina17 (consultado el 9 de agosto de 2018).
} 
Durante las primeras décadas del siglo XX, el interés estatal por la habitación popular se potenció con la llegada del lencinismo ${ }^{10}$ al poder, sin embargo, a pesar de que existieron algunos proyectos de viviendas obreras, estos no llegaron a materializarse y hubo que esperar hasta los años '30 para que se concretaran las primeras experiencias (Cremaschi, 2015).

\section{Los años ‘30: consolidación del modelo habitacional unifamiliar y su difusión en la prensa}

Los modelos familiares diversos antes descritos que, como vimos, eran muy usuales en las primeras décadas del siglo $\mathrm{XX}$, comenzaron a contraponerse más fuertemente a uno uniforme: el matrimonio legítimo e indisoluble, generado por el avance de la integración cultural, propiciado por el Estado y los medios de comunicación (Cosse, 2007). La difusión de este paradigma, que equiparaba la decencia al modelo nuclear, interpelaba a distintos sectores. Se confiaba en el potencial de la familia para crear la integración social mediante valores éticos y morales que aseguraran desarrollo, estabilidad y cohesión a la nación (Cosse, 2004, p. 17). Como a nivel nacional, en la provincia en los años '30 se apostó al fortalecimiento de familia biparental y heterosexual, donde el hombre era el proveedor de bienes (Cerdá, 2011, p. 214). Este modelo familiar fue estimulado mediante la implementación de viviendas sociales estatales que, por su materialidad, condicionaron la ocupación por parte de "cortas familias".

Aunque, como se ha destacado a nivel nacional, durante esta etapa no existió una política extendida de concreción de hábitat popular, ni una acción directa sistemática y planificada (Pérez, 2012, p. 45), en Mendoza comenzaron a concretarse los primeros programas de viviendas populares $\mathrm{u}$ obreras, cuyos destinatarios eran las familias nucleares de los sectores de menores ingresos. Basándose en los diagnósticos desalentadores sobre la habitación y como expresión material de la intención del Estado de mejorar las condiciones de existencia y promover el modelo unifamiliar, se llevaron a cabo las conocidas casas colectivas en la provincia de Mendoza. Eran monobloques de departamentos de 2, 3 y 4 dormitorios, lo que condicionaba que fueran ocupados por una sola familia (Figura III). Estos edificios albergarían a alrededor de tres mil personas y estaban destinados a obreros y empleados modestos del Estado.

\footnotetext{
10 Fue una facción antipersonalista del radicalismo provincial que gobernó intercaladamente con
} intervenciones federales desde 1918 hasta la década de 1930. 
63 | La vivienda estatal y su contribución al fomento...

Figura III Fotografía de la inauguración de las Casas Colectivas. 1936

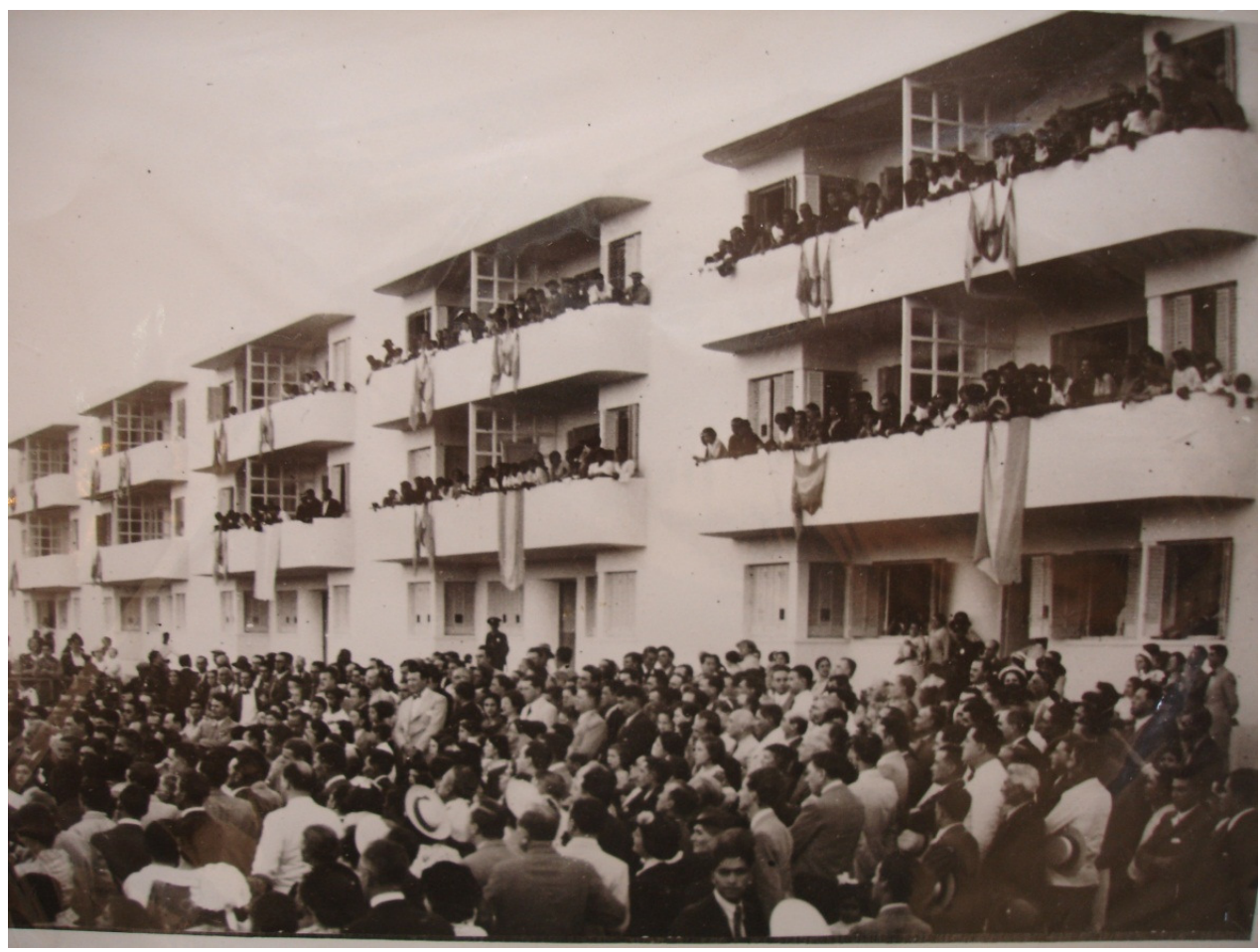

Fuente: Archivo General de la Provincia de Mendoza.

Según los dichos de su principal impulsor, el gobernador Guillermo Cano, estas viviendas resultaban "una verdadera escuela (...) en la cual las familias modestas aprenderán a mejorar su standard de vida, en un ambiente cómodo y armónico, que el Estado hará respetar y que les dará la preparación necesaria para adquirir y conservar más tarde, la casa propia" (Cano en Raffa, 2004, s/p). Las unidades serían dadas en alquiler por el Estado a particulares, por tanto, para el mandatario, eran una transición de una situación habitacional indigna (conventillo, casa de pensión, casa compartida con otras personas, etc.) a otra deseable, cuyo punto cúlmine era la adquisición de la propiedad privada. Así es que la vivienda era una escuela que, por sus propias características, materiales aseguraba el perfeccionamiento de las costumbres cotidianas. El Estado brindaría tutela y asesoramiento hasta que las familias estuvieran capacitadas para afrontar la responsabilidad que implicaba poseer un hogar propio.

Las casas colectivas eran vistas como un escalón en este camino en que los beneficiarios debían "aprender" las normas de vivir "decentemente". En Los Andes se observa claramente esta idea de transición que posibilitaban las viviendas de propiedad horizontal dadas en alquiler:11 “La casa propia es el ideal de dicha. Mientras no se pueda

\footnotetext{
11 En 1948, se creó la ley de propiedad horizontal que estableció la posibilidad de que los departamentos fueran considerados propiedades individuales y por ende fuera posible ponerlos a la venta, aunque 
realizar tal anhelo habrá de acudirse al albergue confortable y económico que proporciona el Estado". ${ }^{12}$

Sin embargo, la construcción de estos bloques de departamento, que parecían un inicio de solución del problema habitacional, fue considerado un agravante de la situación por su pequeña escala, ya que "muchos ciudadanos que alquilaban casas más o menos grandes en el centro de la ciudad, por «snobismo» han alquilado en las Casas Colectivas, dejando vacías las que ocupaban en el centro de la ciudad, viéndose sus dueños obligados a alquilarlas por habitación". ${ }^{13}$ Este comentario nos indica, además, que la división de una propiedad para ser subalquilada seguía siendo una práctica común en los años '30 en Mendoza y que, por consiguiente, la implementación de estos departamentos había ido en detrimento del fomento de este modelo familiar deseado. ${ }^{14}$

Durante esta etapa, el gobierno de Mendoza planificó, además, un barrio de unidades unifamiliares individuales, ${ }^{15}$ que no fue concretado, pero cuya implementación generó una fecunda discusión sobre si el ideal de vivienda estatal debía construirse mediante casas individuales o en bloque. ${ }^{16}$

Es interesante advertir que, cuando se trataba el problema de la habitación popular, si en la etapa anterior el foco de atención estaba puesto en cuestiones de higiene y salubridad, durante este período se reforzó la trascendencia simbólica que implicaban las condiciones de habitación que impactaban en los comportamientos familiares. Los diarios se hicieron eco de la idea de que "la inmoralidad, el alcoholismo, la degradación y la prostitución eran males aportados por las malas viviendas, serían contenidos por el bien estar que produce un hogar estable y feliz."17 Se consideraba que la habitación saludable "afirma los vínculos de la familia y la relación social". ${ }^{18}$

Como se aprecia, el dispositivo habitacional era observado como una herramienta que afectaba directamente la constitución y el comportamiento familiar. Así es que se

estuviesen en la misma superficie de terreno; además, estableció normas para las áreas comunes. Por ello, antes de esta fecha las viviendas en bloque solo podían ser alquiladas.

${ }^{12}$ Los Andes, 29 de mayo de 1940, En la sesión de anoche en el Concejo Deliberante fue fundada una iniciativa sobre construcción de casa para obreros, p. 6.

${ }^{13}$ Ibíd.

${ }^{14}$ Entre las críticas que han quedado registradas en la prensa figuró el retraimiento de las familias obreras a ocuparlas por los cambios que suponía adaptarse a este diferente modo de habitar (Los Andes, 29 de mayo de 1940, p. 6). El mismo diario denunciaba que su implementación "Restó valores a la individualidad familiar y obligó a vivir en una comunidad que sería posible en los grandes centros de población, pero que no puede aceptarse en Mendoza [...] en nuestra Provincia, el clima, lo mismo que el ambiente y la disposición de grandes extensiones de tierras, obligan a edificar casas individuales con suficiente espacio para mantener una completa división de los grupos familiares que las habitan". Los Andes, 27 de abril de 1946, El verdadero concepto sobre la vivienda obrera, p. 4.

${ }^{15}$ La planta de los proyectos que se difundieron en la prensa tiene una tipología cercana a la vivienda rural. Se observa una galería descubierta que da paso a las habitaciones, la retracción hacia el jardín interior y la huerta, y la consiguiente escasa relación con el entorno urbano, finalmente, estaban equipadas con una "cocina económica" equipada a leña que brindaba calefacción y agua caliente al hogar (Cremaschi, 2016).

${ }^{16}$ Para profundizar en esta discusión puede consultarse Cremaschi, 2015.

${ }^{17}$ Los Andes, 27 de febrero de 1936, Construcción de casas colectivas, p. 16.

${ }^{18}$ Los Andes, 18 de enero de 1942, Proyéctase la creación de ciudades -parque y barrios- jardines en varios departamentos y zona de influencia de esta ciudad, p. 7. 
consideraba que con la creación de una habitación digna: "se reforzarán los lazos familiares, se fortalecerá el amor por el hogar, enlazando más fuertemente al ciudadano con el suelo patrio". ${ }^{19}$ Así es que la casa no era importante solo por su salubridad, sino que, para el ciudadano, había cobrado trascendencia como el "centro amable de su afecto." ${ }^{20}$ Esta nueva función del hogar colaboraba a crear una raza "moral y físicamente fuerte." ${ }^{21}$ La casa estimulaba estas prácticas positivas asociadas a la "familia legítima", ya que se consideraba que tendía a "una afirmación del núcleo y traduce el sentimiento de responsabilidad a que es conducido el hombre través de sus obligaciones y deberes." 22 Como vemos, no solo colaboraban en mejorar las condiciones objetivas de vida, sino que contribuían a la armonía, la unidad familiar y el patriotismo. Tenían injerencia en aspectos simbólicos y, no exclusivamente en la salubridad, por tanto, colaboraban y eran expresión del anhelo de formar familias moralmente bien constituidas.

Figura IV. La propaganda política de la época y las comparaciones entre dos formas distintas de habitar

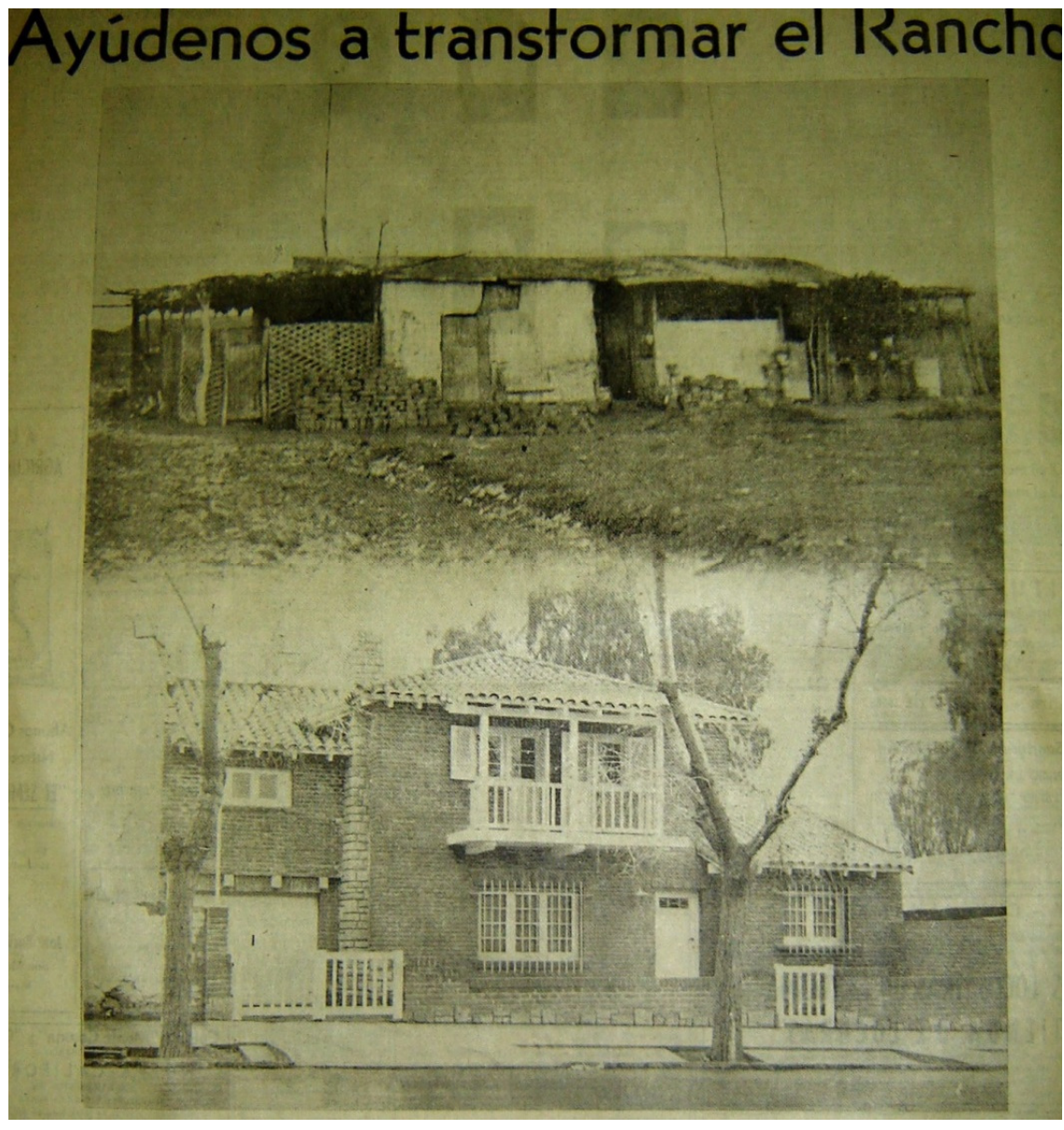

\footnotetext{
${ }^{19}$ Los Andes, 5 de julio de 1942, Ayúdenos a transformar el rancho, p. 12.

${ }^{20}$ Ibíd.

${ }^{21}$ Ibíd.

${ }^{22}$ Los Andes, 18 de enero de 1942, Proyéctase la creación de ciudades -parque y barrios- jardines en varios departamentos y zona de influencia de esta ciudad, p. 7.
} 
Como observamos, el modelo de vivienda unifamiliar estaba legitimado ampliamente por la prensa y la opinión pública, por lo tanto, difundido como el ideal al que debían aspirar las familias (Figura IV).

A pesar del empleo de la vivienda como herramienta que condicionaba las prácticas familiares, del esfuerzo oficial por orientar los modelos no deseables y de la gran difusión de representaciones positivas en la prensa, los cambios no tuvieron gran impacto. Así, observamos que, en Mendoza, hacia el final del período (1943), el Censo Escolar de la Nación revelaba que en Argentina esta provincia era la que tenía mayor porcentaje de familias compartiendo un hogar (51\%). De este índice, el 69,5\% estaba constituido por grupos de entre 4 y 6 familias asiladas en una misma casa y el 23,9\% representaba el hacinamiento de entre 7 y 10 familias por unidad (Cerdá, 2011, p. 200). En la capital de la provincia existían 6.002 familias que vivían en una sola habitación, mientras que en 3.232 casos 2 o 3 familias compartían una casa. ${ }^{23} \mathrm{El} 66 \%$ de estas familias vivía en zonas urbanas, el $6 \%$ en zonas semiurbanas y el $27,6 \%$ en zonas rurales. ${ }^{24}$ Además del hacinamiento colectivo, este Censo evidenció que, sumada a la costumbre de compartir una unidad por distintos grupos familiares, persistía la cohabitación individual. Así es que, en Mendoza, en el 80\% de las familias, 4 o 5 individuos compartían una misma habitación. ${ }^{25}$ En definitiva, estos paradigmas que el Estado intentaba aplicar no tuvieron un efecto visible en la realidad social. Frente a este diagnóstico desalentador, el peronismo redobló los esfuerzos en la concreción material y en la difusión por medio de la propaganda del modelo de habitar considerado adecuado.

\section{El primer peronismo y el empleo masivo de la vivienda como herramienta de trasformación social}

La situación de hacinamiento individual y colectivo antes descrito persistió hasta bien entrado el período peronista. En 1949 se daba a conocer un estudio realizado por el Instituto de Investigaciones Económicas y Tecnológicas de la provincia de Mendoza que estudiaba familias pertenecientes a distintos sindicatos y cuyos números demostraban que, de las 206 familias relevadas, 45 vivían en una sola pieza, 107 en 2 habitaciones, 45 en 3 y solamente 9 familias ocupaban casas que contaban con 4 cuartos. ${ }^{26}$ Como en los períodos anteriormente analizados, para la opinión pública, esta situación propiciaba enfermedades y hasta "prácticas no compatibles con la moral". ${ }^{27}$ Esto seguía considerándose como un peligro, no solamente desde la visión de la salubridad pública

${ }^{23}$ Los Andes, 5 de octubre de 1945, 6.000 familias ocupan viviendas de una sola habitación en la ciudad de Mendoza, p. 5.

${ }^{24}$ Ibíd.

${ }^{25}$ La Libertad, 10 de mayo de 1944, La vivienda popular en Maipú y Godoy Cruz, s/p.

${ }^{26}$ Los Andes, 15 de septiembre de 1949, Un grave aspecto del problema de la vivienda, p. 4.

${ }^{27}$ Ibíd. 
67 | La vivienda estatal y su contribución al fomento...

y de las condiciones de higiene, sino también porque: "Los movimientos sindicales de tinte exasperado y las propias doctrinas extremistas, cuentan allí con amplio campo para su aclimatación." ${ }^{28}$ Como se observa, y en continuidad con las ideas de etapas anteriores, se consideraba que estas formas de habitar propiciaban la dispersión de ideologías que debían ser combatidas.

En cuanto a los conventillos, las críticas perduraron y en 1943 el diario La Libertad consignaba que existían cerca de 107 activos en la ciudad de Mendoza. Estos subsistían a pesar de que ya no era tan conveniente económicamente para los propietarios debido a que la ley de alquileres dispuso que este tipo de habitación bajara un $50 \%$ de su valor. ${ }^{29}$ Sin embargo, y a causa del poco control y la escasez de unidades, esta ley no era cumplida por los propietarios, que seguían exigiendo condiciones insólitas como el adelanto de hasta dos años de alquiler. ${ }^{30}$ Siguiendo las tendencias anteriores, para la opinión pública, la vida en estos tipos habitacionales generaba malos hábitos y se los relacionaba con las conductas sociales reprobables: “El núcleo familiar, que es básico en nuestras sociedades, no puede elevar su moral en el ambiente de los conventillos, en la promiscuidad peligrosa o en la sordidez de las habitaciones malsanas. Todos estos factores convergen en una incidencia negativa, creando pesimismo y desaliento, fomentando hábitos antisociales." ${ }^{31}$ Estos artículos y guarismos nos indican tanto la pervivencia de conventillos y la tendencia a compartir las viviendas, como la falta de interés por parte de los propietarios en reconvertir esas propiedades en unidades más adecuadas.

Con la llegada del peronismo al poder, el problema de la vivienda, que como vimos anteriormente había sido incipientemente abordado por los gobiernos de otros períodos, comenzó a ser tratado más sistemáticamente. Decantaron en estos años las discusiones que se habían dado en etapas anteriores sobre la problemática de la vivienda, generándose un incremento significativo en el número de unidades concretadas. Esto fue posible debido a que se constituyeron los mecanismos burocráticos e institucionales para que su abordaje fuera masivo y se extendiera a todo el país. Así, en 1944, se disolvió la Comisión Nacional de Casas Baratas, sustituyéndose por la Dirección de Vivienda y, luego, por la Administración Nacional de la Vivienda (1945), organismos que recibieron mayor financiamiento sobre todo por parte del Banco Hipotecario Nacional (Gargantini, 2013, p. 7). Estas transformaciones se intensificaron en 1946, año en que se reestructuraron las funciones del Banco Central, del Banco de la Nación Argentina, del Banco Hipotecario Nacional y del Banco Industrial. Fue con la flexibilización de los créditos de estas entidades que se percibió una intensa actividad constructiva en el interior del país (Lecuona, 2001, p. 50).

\footnotetext{
${ }^{28}$ La Libertad, 10 de mayo de 1944, La vivienda popular en Maipú y Godoy Cruz, s/p.

${ }^{29}$ La Libertad, 24 de noviembre de 1943, La vivienda del pobre, s/p.

${ }^{30} \mathrm{La}$ Palabra, 4 de septiembre de 1953, Se especula descaradamente con la locación de viviendas, s/p.

${ }^{31}$ Los Andes, 18 de septiembre de 1947, La vivienda popular, p. 5.
} 
La preocupación por la situación habitacional de los sectores más desprotegidos y económicamente insolventes tenía su paralelismo en una política estatal en que la familia tenía un lugar destacado. La importancia que le otorgó el peronismo al tema familiar se percibe en que la familia fue tomada como unidad de análisis en el censo de 1947. En los censos anteriores $(1869,1895$ y 1914) no se había investigado el número de familias que integraban la población, sino que se había seguido un concepto de carácter individualista, que solamente entendía a la Nación como la suma de personas. La información familiar se consideró trascendente, puesto que permitía "la interpretación de muchos fenómenos sociales relacionados con la natalidad, la salubridad e higiene, las condiciones de vida, económicas y culturales, etc."32 A los efectos censales se contabilizó como integrantes de la misma familia a todas las personas unidas por el vínculo del parentesco y la dependencia económica o familiar con el jefe de la familia, que habitaran en la misma casa e, incluso, al personal de servicio, pensionistas o huéspedes, si los hubiere. Los hijos casados, su cónyuge y sus hijos, eran una familia censal distinta, aunque vivieran en una misma casa. ${ }^{33}$ Sin embargo, como ha destacado Cosse, este interés por las familias se redujo a aquellas instituidas jurídicamente (2004, p. 7) y las naturales no fueron investigadas. Este criterio excluyente, en un censo considerado de gran calidad técnica, indica la decisión de leer los comportamientos reproductivos de la población según la idea de familia legítimamente instituida y socialmente aceptada por parte de los sectores medios y altos (Cosse, 2004, p. 8). Es necesario no olvidar que, si bien en la época las situaciones de convivencia fuera de la ley eran sinónimo de falta de progreso, las mismas no eran la excepción, sino la regla. Oficialmente, el concubinato era juzgado de forma negativa, así se aprecia en los comentarios al Censo de 1947 en que se enunciaba: "Son estas uniones, por lo general, una consecuencia de la miseria y la ignorancia y, sólo por excepción, de la mala fe o la inadaptación social. De aquí que ellas son proporcionalmente más numerosas en las zonas más atrasadas y pobres". ${ }^{34}$ Esto es interesante, puesto que, como veremos más adelante, la propuesta de vivienda popular apuntaba a afianzar este modelo, invisibilizando otros posibles, que, como se ha consignado, eran muy corrientes por estos años. A pesar de que durante el lapso de 19401960, en la región pampeana se percibió una leve tendencia descendente de la ilegitimidad, no hubo un cambio sustancial respecto del pasado. Por otro lado, en los sectores más pobres de Argentina estas tasas continuaron siendo muy altas. Lo mismo

${ }^{32}$ IV. Censo General de la Nación. Población. (1947). Buenos Aires: Dirección Nacional de Estadísticas y Censos, p. LXXVII.

Disponible en: http://deie.mendoza.gov.ar/\#!/censos-nacionales-de-poblacion/1947-cuarto-censo-generalde-la-nacion-42 (Consultado el 9 de agosto de 2018).

${ }^{33}$ Ibíd.

${ }^{34}$ IV. Censo General de la Nación. Población. (1947). Buenos Aires: Dirección Nacional de Estadísticas y Censos, p. LXXIV.

Disponible en: http://deie.mendoza.gov.ar/\#!/censos-nacionales-de-poblacion/1947-cuarto-censo-generalde-la-nacion-42 (Consultado el 9 de agosto de 2018).

Anuario de la Escuela de Historia Virtual - Año 9 - N 14 - 2018: pp. 53-80. ISSN 1853-7049 
69 | La vivienda estatal y su contribución al fomento...

se observa en Cuyo, zona en la que los procesos de control de la natalidad y descenso de la ilegitimidad se produjeron más tardía y lentamente (Torrado, 2003, pp. 267, 336, 355).

Una de las formas de estimular las buenas prácticas familiares se dio a partir de la entrega de beneficios a ciertos modelos familiares. Las políticas redistributivas del peronismo afectaron directamente a la familia, así percibimos el incremento del salario familiar, la disminución de impuestos a las familias numerosas, el fomento de subsidios de préstamos por matrimonio y nacimiento, la prioridad de empleo y acceso a la vivienda a padres de familia (Bianchi, 1999, p. 120). ${ }^{35}$ En esa dirección, el peronismo ofreció a los "desheredados" el horizonte de felicidad de la vida doméstica, hogareña, decente y respetable, sabiendo que muchas veces se ubicaban por fuera del orden familiar instituido (Cosse, 2006, p. 60). Se alcanzaba, de este modo, el estatus de "familia normal" y se modificaba la posición social y simbólica.

La relación entre familia y vivienda no pasó desapercibida entre la dirigencia peronista que interpretó esta simbiosis como natural e indiscutible. Esto se observa en el discurso de creación de la ya mencionada Administración Nacional de Vivienda en el que Perón afirmaba:

... sostenemos que no es posible concebir la idea de familia sin que indisolublemente, como la sombra al cuerpo, esté adherida a ella el espacio vital, el techo, elemento material que cobija y aglutina y a cuyo amparo se expande y florece la vida. De ahí nuestro ideal: "Una vivienda para cada familia, cada familia en su vivienda", y cuya cristalización, tras la cruzada que hemos de emprender al instante, traerá irremisiblemente aparejada una firme y segura armonización social. ${ }^{36}$

El presidente dejaba clara la intención de dotar a cada familia de una vivienda, pero además enfatizaba que los grupos familiares debían ocupar y permanecer en ellas, es decir, debían dedicarse a la vida doméstica y a los asuntos privados. Esta intervención activa en el área habitacional se produjo porque el peronismo propuso un modelo de Estado interventor que regulaba las actividades de la esfera pública y privada. Sintomático de ello es que en 1947 el presidente Perón incluyera la vivienda como un ítem del derecho al bienestar en el artículo VI de los Derechos del trabajador, dado que el mismo era la "expresión mínima de la que todos los trabajadores debían disponer."37. Luego, estos fueron formalmente incluidos en la reforma de la constitución en 1949, lo que fue expuesto como una reivindicación social (Barrios y Fernández, s/f., p. 7). El Estado se transformaba así en el garante por ley de que los trabajadores accedieran a ese

${ }^{35}$ Tanto para la iglesia como para el gobierno la regulación de la familia era un mecanismo de control social. De allí que la peronización de la familia fuera una amenaza para la iglesia, ya que la esfera privada era su jurisdicción. Los conflictos surgieron cuando el Estado comenzó a intentar tener el control de ciertas áreas como la asistencia social, la educación y la familia, antes jurisdicción de la iglesia (Bianchi, 1999, pp. 117, 127).

${ }^{36}$ Perón, J. D. (1945). Discurso con motivo de la Administración Nacional de Vivienda.

Recuperado de: http://constitucionweb.blogspot.com.ar/2010/04/discurso-de-peron-con-motivo-de-la.html. (Consultado el 9 de agosto de 2018).

${ }^{37}$ Los Andes, 13 de septiembre de 1948, Derecho al bienestar, p. 7. 
derecho. Esto le otorgaba a su vez la potestad para decidir sobre las políticas habitacionales y también sobre las tipologías a implementar, es decir, que en él recaía la responsabilidad de diseñar esta herramienta que incidía sobre las relaciones familiares ("sombra y cuerpo", en palabras de Perón) y materializaba las expectativas y deseos de la clase política en torno a ellas. Por eso, la resolución de las malas condiciones habitacionales implicaba solucionar aspectos tangibles, pero también intangibles que se ligaban al imaginario de la familia, la justicia social y el patriotismo. En este contexto la vivienda también era una herramienta de inclusión social que permitía la redistribución de los ingresos propugnada por el peronismo y la concreción de una sociedad más igualitaria. La vivienda era ponderada como “el trono magnífico de la dignificación social". 38

Mendoza no permaneció ajena a este proceso, lo que llevó a la creación del Instituto Provincial de la Vivienda en 1947. Subyacía a su creación el convencimiento respecto a que una de las acciones imperativas para la transformación social era la implementación de programas de viviendas. En palabras del Ministro de Economía, Obras públicas y Riego del primer gobierno peronista de la provincia y uno de los impulsores de la creación del IPV, se observa la acción transformadora de las viviendas: “Si queremos por ende salvar a la humanidad, dignificar al hombre y resguardar la familia, tenemos forzosamente que extirpar el rancho, el tugurio, el conventillo". (Segura, 1948, p. 145).

Los criterios de adjudicación de la vivienda popular construida por el IPV no han quedado explicitados en los acervos consultados. Sin embargo, existen algunas pistas que indican que uno de los factores de mayor peso fue el económico. Este es el caso del barrio 4 de junio cuya licitación en 1946 fue un fracaso, pues, solo se habían adjudicado 10 viviendas. Debido a ello, la convocatoria se amplió de los obreros a los empleados del Estado. No obstante, se impuso un condicionante económico: los ingresos de los adjudicatarios no debían exceder los 350 pesos, calificando también pensionados o jubilados con familia a cargo. ${ }^{39} \mathrm{~A}$ su vez, se dispuso otorgar prioridad a las familias con mejores antecedentes, a las que poseyeran peores alojamientos y a las que estuvieran constituidas por integrantes argentinos. Otro indicio que se percibe en los documentos del IPV, es que durante el mandato de Brisoli el papel de los gremios se hizo más visible en la gestión de la vivienda, $\mathrm{y}$, en muchos casos, estos propusieron a las familias adjudicatarias. También en este período el IPV, seleccionaba y patrocinaba las familias para que tramitaran los créditos hipotecarios para subvencionar las viviendas. Sin embargo, los criterios con que las familias eran seleccionadas no han quedado registrados en los documentos del archivo del IPV.

La casa adecuada, más allá de solucionar temas de higiene, representaba una forma de "existencia socialmente digna". Así es que, en palabras del gobernador Picallo (19461949), se pretendía para el obrero una "vivienda segura que les proteja contra los factores

\footnotetext{
${ }^{38}$ La Libertad, 9 de diciembre de 1943. Infríngese el decreto de rebaja de alquileres, s/p.

${ }^{39}$ La Libertad, 7 de octubre de 1946, Las casas individuales, p. 5.
} 
71 | La vivienda estatal y su contribución al fomento...

naturales, higiénica para que preserve su salud y confortable para que estimule y fortalezca su formación espiritual (...) la buena vivienda es el elemento fundamental no solo para preservar la higiene de su cuerpo sino también para reconfortar su espíritu." (Provincia de Mendoza, 1947, tomo 8, p. 66).

Si bien los conceptos de protección e higiene eran empleados en discursos anteriores como inherentes a la casa, encontramos, durante el peronismo, el novedoso empleo de la noción de confort ligado a la vivienda popular. El confort se sumaba como un "plus", no estrictamente relacionado con las necesidades biológicas, sino con lo espiritual. En definitiva, en este aditivo, en la superación de las expectativas inmediatas de lo que se entendía como vivienda popular, también residía la compensación que exigía la justicia social. La vivienda era considerada no simplemente un cobijo, sino un "estímulo moral" debido a que era un "elemento capaz de satisfacer las necesidades del confort moderno". ${ }^{40}$

La tipología de vivienda construida masivamente que analizaremos más adelante, estaba sustentada, a su vez, por una serie de representaciones en las que se vislumbran las intenciones subyacentes en su implementación. Así, observamos que se destacaba su papel decisivo en el condicionamiento de las relaciones familiares, ya que su construcción contribuía "a la cohesión familiar, por la mayor atracción que brinda la convivencia hogareña". ${ }^{41}$

La influencia en la conformación de la familia no pasó desapercibida por el gobernador Picallo, impulsor del ya citado IPV. Este mandatario señalaba su "decidido propósito de dotar a la población de viviendas confortables y sanas, dada la gravitación decisiva que la misma tiene, no sólo en las costumbres y en la salud, sino en el robustecimiento de la vinculación familiar, base de toda sociedad bien organizada" (Picallo, 1947, p. 80). Dejaba claro, de esta manera, que la vivienda resultaba ser una herramienta útil para fortalecer los lazos familiares, pero no cualquiera de ellos, sino que se aludía específicamente al deseado modelo nuclear, que era para el cual estaban diseñados los modelos de vivienda. Implícitamente, siempre que se hablaba de familia, se aludía a la "decentemente constituida" y no a aquellos otros modos parentales que, como vimos, continuaban siendo muy corrientes.

Otros sectores, además de los gubernamentales apoyaban este modelo y observaban a la vivienda social como una herramienta normalizadora que fomentaba la estructura de familia deseada. En este sentido, resultan interesantes los comentarios de un bodeguero, que, por dotar de vivienda saludable a los contratistas de viña, era tomado como ejemplo por la prensa mendocina. El señor Calise notaba los beneficios económicos que propiciaba el facilitar a los obreros unidades acordes a la vida familiar nuclear, y destacaba así que "los trabajadores que tienen casas cómodas y limpias, en sus trabajos producen más: salen menos de ellas y cultivan más el afecto familiar y reuniones

\footnotetext{
${ }^{40}$ Los Andes, 22 de diciembre de 1946, La vivienda popular a través del discurso presidencial, p. 10.

${ }^{41}$ Los Andes, 23 de septiembre de 1946, Estímulo a la construcción de viviendas, p. 6.
} 
moralmente sanas dentro de ellas con parientes y amigos". ${ }^{42} \mathrm{Si}$ bien este caso corresponde a la iniciativa privada, resulta interesante porque era tomado como una acción digna de ser difundida y repetida por otros particulares. Se aprecia claramente la consideración de la vivienda adecuada como una herramienta que colaboraba para que las actividades de los trabajadores se resolvieran en la compañía de su entorno más cercano, lo que posibilitaba la disciplina y la productividad.

La prensa emitía opiniones en igual sentido. El periódico La Libertad consignaba la misión superadora del cobijo material de la morada en ocasión de inaugurarse un barrio: "estas casas tienen un significado más profundo que el de la simple construcción de ladrillos que aquí vemos ellas están destinadas a albergar familias y a modificar en los pequeños niños que las habiten, la idea que desde su infancia deben formarse de lo que es vivir en un hogar bello". ${ }^{43}$ Se observa aquí que la vivienda era una herramienta que "modificaba" a aquellos que la habitaban, sobre todo a los niños. Un elemento material que impactaba en la educación y que, por su conformación, colaboraba a enseñar a vivir decentemente.

En cuanto a lo tipológico, la vivienda impulsada por los gobiernos peronistas estaba basada en modelos de la etapa anterior. Es decir que no rompió con el feliz estereotipo burgués de la casa confortable y tecnificada que ostentaba la clase media, sino que puso al alcance de los sectores populares en lo material y simbólico una imitación resignificada de estos modelos que ahora estaban al alcance de los estratos trabajadores (Barrios y Fernández, s/f, p. 9). Aquel prototipo que se venía construyendo en las etapas anteriores y que era en pequeña escala una escuela para "el buen vivir" de las clases populares, con los gobiernos de esta etapa fue multiplicado hasta la escala masiva.

El tipo más frecuente correspondía al de plantas compactas (tipo cajón), con equipamiento mínimo para garantizar el bienestar y confort de los ocupantes, placares embutidos, calefón y cocina, baño completo, entre otros (Figura V). Muchas viviendas se caracterizaban por su amplitud o por la posibilidad de ser ampliadas por los futuros propietarios. La totalidad de las viviendas diseñadas estaban pensadas para familias nucleares y con un número reducido de integrantes, es decir, que en su diseño las entidades estatales reparaban más en lo "deseable" que en las realidades familiares concretas que se evidencian en los censos y en las noticias de los diarios anteriormente analizados. En muchos casos, el dormitorio principal del matrimonio estaba diferenciado del resto por su tamaño y por estar equipado con placares embutidos. Esto les otorgaba jerarquía y los diferenciaba de los otros ambientes.

${ }^{42}$ La Palabra, 14 de agosto de 1946, Una encuesta sobre la vivienda rural realizó el centro vitivinícola Argentino, s/p.

${ }^{43}$ La Libertad, 5 de junio de 1945, Quedó inaugurado el barrio “4 de Junio", s/p. 
Figura V. Vivienda del Barrio Villa Evita

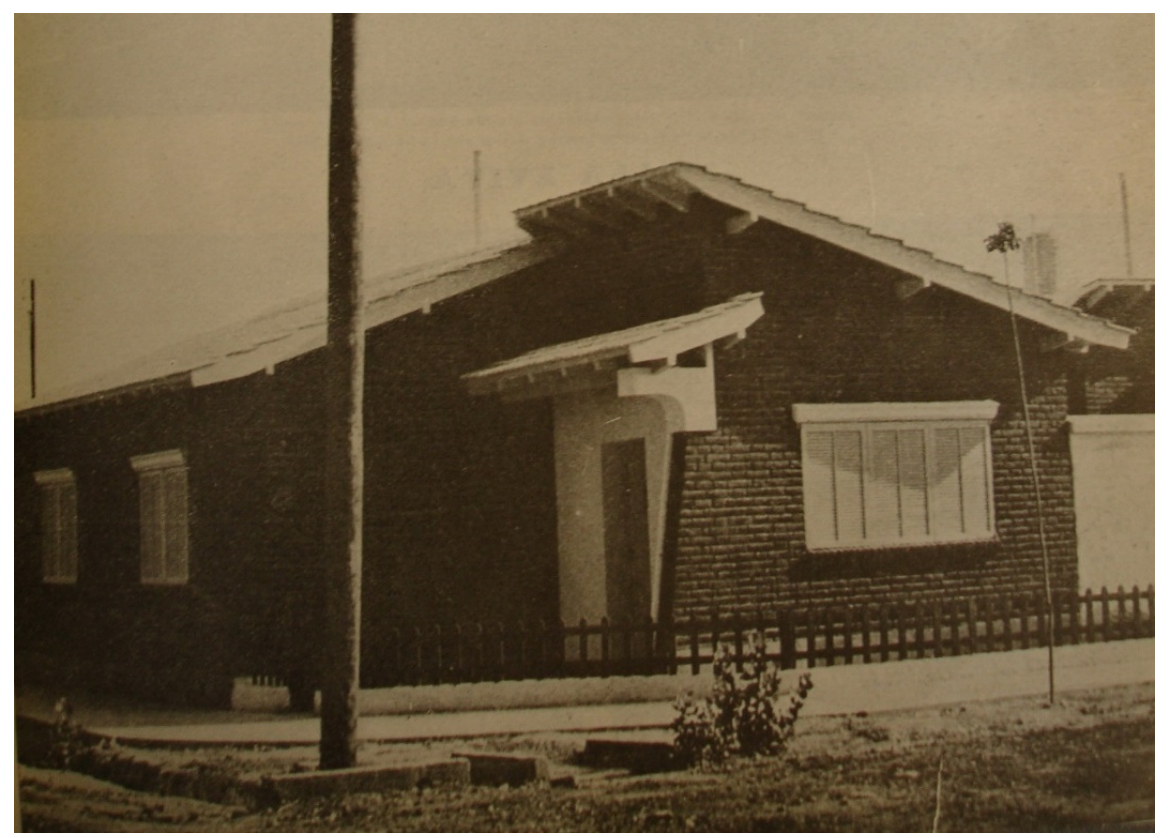

Fuente: Oficina de Prensa e Informaciones del Poder Ejecutivo, 1951, p. 19.

Las viviendas proyectadas por el gobierno provincial de Evans, el último gobernador mendocino de la etapa peronista, estaban pensadas para lo que el poder ejecutivo consideraba una "familia tipo" constituida por un matrimonio y dos hijos. ${ }^{44}$ Lo que resulta realmente sorprendente si se recuerdan los números ya tratados anteriormente sobre el hacinamiento individual y las cifras que dan cuenta de que la familia más usual estaba constituida de una forma bastante diferente. Es decir que este concepto de familia tipo, estaba más anclado en la visión deseada sobre el modelo familiar que sobre los números y la realidad tangible provincial que arrojaban las estadísticas y censos.

Los tipos implementados en esta etapa estaban en concordancia con las ideas nacionalistas y católicas que observaban en esta tipología de casa el hogar de la familia cristianamente constituida y nucleada en torno al matrimonio (Barrios y Fernández, s/f, p. 10). Si bien esta tipología no restringía el número de hijos (Aboy, 2005, pp. 61 y 168) siempre se trataba del modelo nuclear y no se tenían en cuenta familiares de otro grado o allegados. El mismo sentido podemos percibir en Mendoza. En el proyecto de creación del IPV, el artículo séptimo proponía que al nacimiento de un hijo "La ley premiará a la familia eximiéndola del pago de la mensualidad correspondiente por amortización o arrendamiento" (Provincia de Mendoza, 1947, tomo 1, p. 162). Ello, indirectamente, fomentaba el aumento numérico de la familia y propiciaba el carácter tradicional de la misma, en la que la mujer permanecía en la casa a cargo de una abundante prole. Además, si la familia se agrandaba, el tamaño de los lotes permitía ampliaciones

\footnotetext{
${ }^{44}$ La Palabra, 16 de octubre de 1954, El gobierno del Dr. Evans en la solución del impostergable problema de la casa-habitación, s/p.
} 
posteriores, que, en muchos casos, como se aprecia en distintos planos del IPV, se encontraban ya planificadas en los proyectos antes de que comenzaran las obras.

En línea con estas ideas, Segura, que como hemos visto fue impulsor del IPV y, además, coautor junto al gobernador Picallo de la ley 1.658 que creaba la legislación en torno a esta entidad, señalaba que la vivienda a implementarse por parte del Instituto debía tener cuatro ambientes y dependencias, de esta manera no solo servirían para albergar a familias numerosas, sino que permitirían fomentar la procreación. ${ }^{45}$ Este interés por promover las familias numerosas, también se percibe en otros actores, que consideraban que la vivienda podría tener incidencia en las tasas de natalidad y que dotar de una casa adecuada contribuiría al aumento de la población: “El problema de la vivienda es [a] la demografía, lo que la demografía es a la industria. De ahí la urgente necesidad de que el cuestionario de la habitabilidad sea resuelto, si queremos que el de la demografía encuentre carriles de solución". ${ }^{46}$ La concreción de viviendas adecuadas daría por resultado un incremento de la mano de obra industrial, en un momento de fuerte crecimiento de este sector.

En el mismo sentido, el ya citado bodeguero Calise, afirmaba que la construcción de unidades adecuadas incidía en la generación de nuevos núcleos: "una familia que sale a vivir de una tapera para ocupar una casa buena, de inmediato el elemento joven que vive en ella acelera los noviazgos y casamientos". ${ }^{47}$

En la difusión del modelo habitacional ideal, el ícono de la familia nuclear fue empleado en numerosas propagandas de la etapa, tanto las provenientes de la esfera oficial como de las de empresas constructoras privadas que ofrecían sus servicios. Se trataba de un estereotipo nuclear, con sus integrantes siempre bien vestidos, frente a la naif casita de tejas que representaba el ascenso social y la posibilidad de ser felices (Cremaschi, 2013). Marcaba el anhelo al que ahora podían aspirar los trabajadores, que consistía no solo en poseer una vivienda adecuada, sino también una familia socialmente aceptada, normalmente constituida (Figura VI).

${ }^{45}$ La Palabra, 15 de enero de 1948, Interesantes declaraciones del ministro de Economía y O. Públicas Sr. Segura, s/p.

${ }^{46}$ La Palabra, 6 de mayo de 1948, El problema de la Vivienda, s/p.

${ }^{47}$ La Palabra, 14 de agosto de 1946, Una encuesta sobre la vivienda rural realizó el centro vitivinícola Argentino, s/p. Estas preocupaciones pueden haber estado enmarcadas en la baja de la natalidad que se observó a inicios de la década de 1930, ya que descendió un 30\%, valor que indica un control voluntario con métodos anticonceptivos por parte de la población (Torrado, 2003, p. 87). Sin embargo, entre 1945 y 55, hubo una inversión en la tendencia de la natalidad que luego recobró su moderada propensión descendente. (Ibíd., 2003, p. 88). 
75 I La vivienda estatal y su contribución al fomento...

Figura VI. Propaganda del programa de viviendas difundido en la prensa local

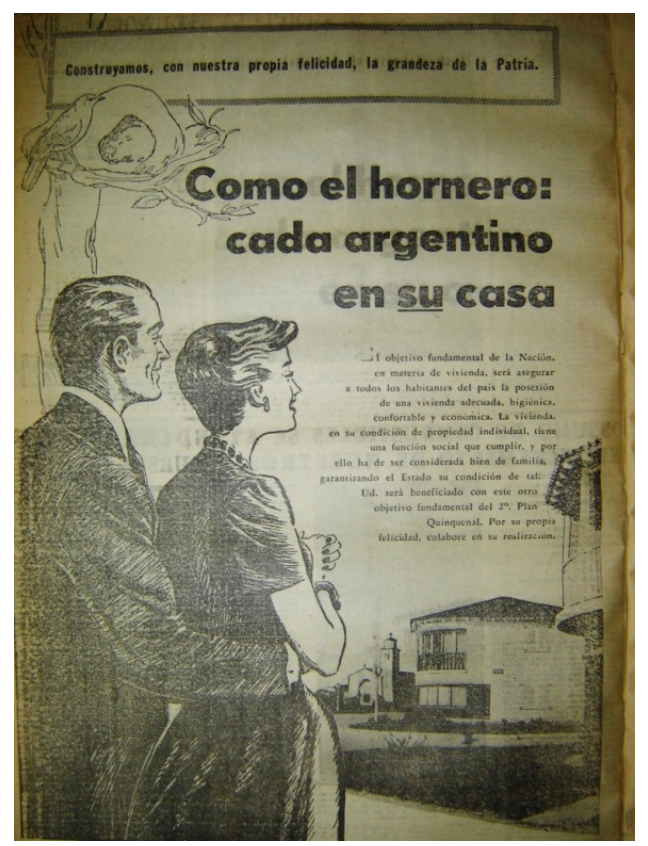

Fuente: La Libertad, 16 de abril de 1953, p. 8.

Por otro lado, y en consonancia con la propaganda, es interesante que en el año 1950 se dio impulso a la vivienda como Bien de Familia, que refería a que la función social estaba dirigida preferentemente a la vivienda de familia constituida. Así es que "La vivienda en su condición de propiedad individual tiene una función social que cumplir y por lo tanto ha de ser considerada un bien de familia". ${ }^{48} \mathrm{El}$ mandato era categórico y en el mismo anuncio exhortaba: "Por su propia felicidad, colabore en su realización". ${ }^{49}$

\section{Conclusiones}

A lo largo de este trabajo hemos podido constatar la consolidación de un tipo de vivienda estatal destinada a albergar familias nucleares. Observamos así la preocupación de la prensa y las cifras alarmantes arrojadas por los censos nacionales, que sirvieron de diagnóstico de la situación de convivencia y cohabitación. Esta visión negativa de la realidad habitacional condujo a las experiencias incipientes en los años '30 apoyadas en las representaciones positivas del modelo nuclear legitimado. Posteriormente, apreciamos la construcción masiva por parte del peronismo y la consiguiente difusión de un modelo de vivienda que propiciaba la convivencia de los familiares directos y reorientaba organizaciones familiares alternativas.

\footnotetext{
${ }^{48}$ La Libertad, (16 de abril de 1953) Como el hornero: cada argentino en su casa, p. 8.

${ }^{49}$ Ibíd.
} 
Durante los años peronistas, hemos observado que la vivienda cómoda y confortable era promocionada como un avance en materia de justicia social y como parte de la redistribución de los ingresos que había propiciado el momento político. Sin embargo, en este trabajo consideramos que las acciones en materia habitacional también pueden interpretarse a partir de su intención tendiente a controlar las prácticas familiares no deseadas que como analizamos abundaban en esta época y eran observadas negativamente por los actores gubernamentales y la opinión pública. La democratización del acceso a la vivienda también implicó la difusión de una "democratización de un modelo de habitar y por tanto uno familiar de clase media" (Pérez, 2012, p. 69), que era señalado por el Estado como la forma "correcta" y "decente" de vivir, lo que implicaba la condena de los otros modos de organización familiar.

Es decir, entendemos que la vivienda puede haber sido empleada como un medio o herramienta que ayudara a normalizar aquellas situaciones de convivencia no deseadas o no legitimadas y así reorientar estos comportamientos considerados negativos, que eran comunes en los estratos de menores ingresos. Estos indicios demuestran la intención del Estado de regular estas prácticas no deseadas como un intento de disciplinamiento y homogeneización (Ballent y Liernur, 2014, p. 189).

El beneficio de la comodidad y el confort que eran difundidos en discursos anteriormente analizados, también implicaba implícitamente herramientas que tendían a instaurar la paz. Una vivienda cómoda que invitara a permanecer en ella ayudaría a cumplir aquel precepto indicado por Perón que tendía a perpetuar la tranquilidad social mediante la recomendación al asalariado que debía conducirse "del trabajo a casa y de casa al trabajo". ${ }^{50}$ En esta frase, Mariano Plotkin (2007, p. 52) observa "una clara ilustración del papel pasivo que él atribuía a las masas trabajadoras". Esta interpretación está en línea con la que proponen otros autores respecto a que la preocupación del peronismo por la paz social, el crear un orden que fuera capaz de armonizar las exigencias legítimas de los sectores sociales, también conllevaba la idea de neutralizar los efectos desestabilizadores de las luchas de clases (Torre, 2002, p. 58).

Por lo expuesto, consideramos que es posible comprender a la vivienda como un dispositivo de seguridad en sentido foucaultiano, ${ }^{51}$ que el Estado empleó como herramienta para reorientar y controlar costumbres familiares no deseadas. La materialidad de las viviendas impulsadas por el Estado condicionaba las formas de habitar y, por consiguiente, la estructura de las familias que compartían el techo. Esta

\footnotetext{
50 Perón, J. D. (1945). Discurso de Juan Domingo Perón en septiembre de 1945. Buenos Aires. Recuperado de http://sedici.unlp.edu.ar/handle/10915/27174. (Consultado el 9 de agosto de 2018).

${ }^{51}$ Entendemos que un dispositivo de seguridad no se caracteriza por tener un código como el jurídico y tampoco por ser un mecanismo disciplinario, sino que es el conjunto de los fenómenos que indican las medidas óptimas y delimitan lo aceptable (Foucault, 2006, pp. 20-21). Este mecanismo deja hacer, sin prohibir ni prescribir, y aunque eventualmente emplee algunos instrumentos vinculados con la interdicción y la prescripción, tiene la función esencial de responder a una realidad de tal manera que la respuesta la anule, la limite, la frene o la regule (Ibíd., p. 69).
} 
77 | La vivienda estatal y su contribución al fomento...

materialidad, a su vez, se encontraba ampliamente respaldada por una serie de ideas vertidas en discursos, propagandas y artículos periodísticos.

Sin embargo, a pesar de la enorme difusión de este modelo habitacional por medio de su construcción y de la propaganda, observamos que persistió una coexistencia de distintas pautas de comportamiento familiar hasta finales de los años sesenta (Pérez, 2012, p. 25). La heterogeneidad de las prácticas y formas de organización se mantuvo paralela al proceso de consolidación del modelo nuclear como pauta homogeneizadora de la organización doméstica (Aboy, 2008, p. 358). Así, por ejemplo, en Mendoza observamos que en 1960 pervivían en la ciudad 2.183 casas de inquilinato. ${ }^{52}$ Además, de un total de 104.907 viviendas 4.301 tenían más de 4 ocupantes por cuarto. ${ }^{53}$

\section{Referencias bibliográficas:}

Aboy, R. (2005). Viviendas para el pueblo. Buenos Aires: Fondo de Cultura Económica.

Aboy, R. (2008). Arquitecturas de la vida doméstica. Familia y vivienda en Buenos Aires, 1914-1960. Anuario IEHS, 23, 355-384.

Bajtin, M. (1999). Estética de la producción verbal. México: Siglo XXI.

Ballent, A. (2001). Un hogar para cada familia; cada familia en su hogar. En M. Boleda y M. Herrera (Eds.), Seminario sobre Población y Sociedad en América Latina, SEPOSAL 2000 (pp. 317-332). Salta: GREDES.

Ballent, A. y Liernur, J. F. (2014). La casa y la multitud. Buenos Aires: Fondo de Cultura Económica.

Barrios, R. y Fernández, N. (s.f.). (Con) vivir con el peronismo. Vivienda y ciudad durante el primer peronismo. Recuperado de:

URL: redesperonismo.com.ar/archivos/CD1/EPP/barrios.pdf (consultado 15/07/2018).

Bianchi, S. (1999). Catolicismo y peronismo. La familia entre la religión y la política. 19451955. Boletín del Instituto de Historia Argentina y Americana. "Dr. Emilio Ravignani", 19, 115-137.

Bourdieu, P. (2001). Las estructuras sociales de la economía. Buenos Aires: Manantial.

Cerdá, J. M. (2007/2008). Características de la vivienda mendocina de la primera mitad del siglo XX. Población y Sociedad, 14/15, 33-70.

Cerdá, J. M. (2011). Condiciones de vida y vitivinicultura. Mendoza, 1870- 1950. Buenos Aires: Universidad Nacional de Quilmes.

Cerdá, J. M. (s.f.). El mercado de trabajo y las condiciones de vida en Mendoza a comienzos del siglo XX. Recuperado de: http://cdn.fee.tche.br/jornadas/2/H7-02.pdf

Cirvini, S. (2004). Nosotros los arquitectos. Mendoza: ZETA.

\footnotetext{
${ }^{52}$ Censo Nacional de Vivienda. Tomo II (1960). Buenos Aires: Dirección Nacional de Estadísticas y Censos. p. 546.

${ }^{53}$ Ibíd., p. 904.
} 
Cirvini, S. y Manzini, L. (2010). Las casas de la Constructora Andina. Vanguardia arquitectónica del primer Centenario de Mayo (Mendoza-Argentina). Revista de Historia Americana y Argentina 45, 135-175.

Cirvini, S. y Manzini, L. (en prensa). Las viviendas en el patrimonio arquitectónico de Mendoza. Apuntes. Revista de Estudios sobre Patrimonio Cultural.

Cosse, I. (2004). Filiación ilegítima y familia en la Argentina de la primera mitad del siglo XX. Una aproximación desde la producción y la interpretación estadística. VI Jornadas de Sociología. Facultad de Ciencias Sociales, Universidad de Buenos, (pp. 1-33). Recuperado de: URL: http://www.aacademica.org/000-045/270 (consultado 10/05/2018).

Cosse, I. (2006). Estigmas de nacimiento: Peronismo y orden familiar 1946-1955. Buenos Aires: Fondo de Cultura Económica.

Cosse, I. (2007). Ilegitimidades de origen y vulnerabilidad en la Argentina de mediados del siglo XX. Nuevo Mundo Mundos Nuevos [En ligne]. Recuperado de: URL: http://nuevomundo.revues.org/12502. (consultado 10/03/2018).

Cremaschi, V. (2011). La categoría de lo moderno y su aplicación a la arquitectura latinoamericana. El caso del estilo neocolonial en Mendoza. Palapa. Revista de Investigación Científica en Arquitectura vi (ii [13]), 53-61.

Cremaschi, V. (2013). El empleo de la arquitectura en los medios de prensa. Precisiones sobre la propaganda política del primer peronismo en la provincia de Mendoza (Argentina). Cuadernos del Sur Historia, 42, 49-68.

Cremaschi, V. (2015). La vivienda mendocina en el período 1930-1943. Discusiones sobre su implementación. Historia Americana y Argentina, 15 (1), 191-224.

Cremaschi, V. (2016). Los barrios construidos durante el primer peronismo en Mendoza, Argentina. Instituciones y estrategias. Cuadernos de la Universidad de Jujuy, 50, 35-55.

Foucault, M. (2006). Seguridad, territorio, población; curso en el College de France 1977-1978. Buenos Aires: Fondo de Cultura Económica.

Gargantini, D. (2013). Revisión histórica de las políticas de vivienda argentinas implementadas como respuestas a la problemática socio habitacional. Recuperado de URL:

http://blog.ucc.edu.ar/ssh/files/2012/03/Revisi\%C3\%B3n-hist\%C3\%B3rica-de-

pol\%C3\%ADticas-habitacionales_Gargantini.pdf (Consultado 10/03/2018)

Gil Montero, R. (2007). ¿Métodos, modelos y sistemas familiares o historia de la familia?

En D. Robichaux (Comp.). Familia y Diversidad en América Latina. Estudios de casos (pp. 77-101). Buenos Aires: CLACSO.

Lecuona, D. (2001). Conceptos políticos y sociales sobre el problema de la vivienda en Argentina a mediados del siglo XX. Revista INVI, 16 (42), 7-59.

Liernur, J. F. (1999). Casas y jardines. La construcción del dispositivo doméstico moderno. (1870-1930). En F. Devoto et al (Dirs.). Historia de la vida privada en la Argentina. La Argentina plural: 1870-1930 (pp. 99-137). Buenos Aires: Taurus.

Manzini, L. (2011a). Las viviendas del siglo XIX en Santiago de Chile y la región de Cuyo en Argentina. UNIVERSUM, 2, 165-186. 
79 | La vivienda estatal y su contribución al fomento...

Manzini, L. (2011b). El carácter simbólico de las casas patronales vitivinícolas de Mendoza, Argentina (1880-1930). Andinas, 0, 28-41.

Manzini, L. (2012). La casa patronal vitivinícola, un modelo identitario en tiempos del modernismo, en la Región de Cuyo, Argentina (1885-1910). Revista Historia de América, 146, 33-60.

Schmulevich, N., et al. (2014). La vivienda obrera en Argentina. Experiencias de gestión patronal y estatal en las provincias de Mendoza, Córdoba y Tucumán (1880-1980). Ponencia presentada en Seminario, De la vivienda obrera a la vivienda de protección oficial. Madrid.

Oficina de Prensa e Informaciones del Poder Ejecutivo (1951). Agua, vivienda y salud. Mendoza.

Pérez, I. (2012). El hogar tecnificado. Familias, género y vida cotidiana 1940- 1970. Buenos Aires: Biblos.

Picallo, F. (1947). Mensaje del Gobernador de Mendoza. Mendoza: Imprenta oficial.

Plotkin, M. B. (2007). Mañana es San Perón. Propaganda, rituales políticos y educación en el régimen peronista (1946-1955). Buenos Aires: EDUNTREF.

Provincia de Mendoza (1947, tomo 1 y 8). 18 meses de gobierno. Documentación Principal de la gestión administrativa del Poder Ejecutivo de la Provincia de Mendoza. Desde el 26 de mayo de 1946 hasta el 31 de diciembre de 1947. Bajo el gobierno del Sr. Francisco Picallo. Mendoza.

Raffa, C. (2004). Un pueblo para 3000 habitantes: las primeras Casas Colectivas para obreros y empleados estatales en Mendoza, 1935-1938, Revista de Historia de América, $134,115-139$.

Raffa, C. (2010). Los campos técnico y político en la regulación del espacio público. El caso de Mendoza, Argentina, en los años treinta. Palapa, V (10), 17-31.

Raffa, C. y Manzini, L. (2014). El conventillo y la vivienda masiva. Medio siglo de historia sobre los espacios domésticos para sectores populares, en el Área Metropolitana de Mendoza (Argentina, 1900-1955). URBANA - Revista Eletrônica do Centro Interdisciplinar de Estudos sobre a Cidade, 6, 240-271.

Ramos, J. (1999). Arquitectura del habitar popular en Buenos Aires: el conventillo. Buenos Aires: Seminario de Crítica. Instituto de Arte Americano e Investigaciones Estéticas.

Richard-Jorba, R. (2011). Los gobiernos lencinistas en Mendoza. Salud pública y vivienda popular, 1918-1924. Avances del Cesor, VIII (8), 31-62.

Richard-Jorba, R. (2012). Modernización capitalista y pobreza en Mendoza, Argentina. Desarrollo agroindustrial y condiciones de vida de los sectores populares. 18901916. Antítesis, 5 (9), 441-474.

Segura, J. I. (1948). Jorge I. Segura. Ministro de Economía, Obras públicas y Riego. Discursos. Mendoza: Imprenta oficial.

Torrado, S. (2003). Historia de la familia en la Argentina moderna (1870-2000). Buenos Aires: Ediciones de La Flor. 
Torre, J. C. (2002). Introducción a los años peronistas. En J. C. Torre (Ed.), Nueva Historia Argentina. Tomo 8. Los Años Peronistas (1943-1955) (pp. 11-77). Buenos Aires: Sudamericana.

Verón, E. (2004). Fragmentos de un tejido. Barcelona: Gedisa.

Para citar este artículo:

Cremaschi, Valeria (2018). La vivienda estatal y su contribución al fomento de la familia nuclear. El caso de Mendoza durante la primera mitad del siglo XX. Anuario de la Escuela de Historia Virtual, 14, 53-80. 